\title{
Performance and Efficiency Simulation Study of a Smart-Grid Connected Photovoltaic System
}

\author{
Warsame H. Ali, Penrose Cofie, John H. Fuller, Savitha Lokesh, Emmanuel S. Kolawole* \\ Department of Electrical and Computer Engineering, Prairie View Texas A\&M University, Prairie View, TX, USA \\ Email: *ekolawoles2011@yahoo.com
}

How to cite this paper: Ali, W.H., Cofie, P., Fuller, J.H., Lokesh, S. and Kolawole, E.S. (2017) Performance and Efficiency Simulation Study of a Smart-Grid Connected Photovoltaic System. Energy and Power Engineering, 9, 71-85.

https://doi.org/10.4236/epe.2017.92006

Received: November 12, 2016

Accepted: February 7, 2017

Published: February 10, 2017

Copyright () 2017 by authors and Scientific Research Publishing Inc. This work is licensed under the Creative Commons Attribution International License (CC BY 4.0).

http://creativecommons.org/licenses/by/4.0/

\begin{abstract}
The availability of non-renewable energy sources such as crude oil, natural gas, coal etc., is fast diminishing. So the renewable energy sources such as solar, hydropower, geothermal, wind, tidal energy, are gaining more and more importance. Many new developments to convert these renewable energy sources into usable forms are taking place. Most renewable energy sources are used to produce electricity. In this paper, a performance and efficiency simulation study of a smart-grid connected photovoltaic system using Chroma DC programmable power supply, AC programmable source and an Aurora Inverter is proposed. The simulation is performed in MATLAB environment where the Current-Voltage (I-V) and Power-Voltage (P-V) curves from the solar array simulator are generated and plotted. The proposed topology has been verified with satisfactory results. In addition, temperature and irradiance effects on I-V and P-V characteristic curves are verified. Also, the efficiency curves of the photovoltaic grid interface inverter are generated in the study. The MATLAB code developed in this paper is a valuable tool for design engineers comparing different inverters, calculating the optimum efficiency of a given inverter type.
\end{abstract}

\section{Keywords}

Smart-Grid, Photovoltaic System, Renewable and of Non-Renewable Energy, Current-Voltage (I-V) and Power-Voltage (P-V) Curves, Inverter, Electricity

\section{Introduction}

Nowadays, we are mainly dependent on nonrenewable energy sources which are one of the major contributors of environmental pollution and climate change. Due to all these problems and diminishing supply of nonrenewable energy sources, finding a quick, suitable and better alternative like renewable energies are necessary. Demand for green power or renewable energy sources like wind 
power, tidal power, solar power and fuel cells have increased over the years. Now one of the greatest challenges is to make use of these renewable energies more efficiently and cost effectively. Solar energy has been one of the attractive sustainable sources. Solar cells are simply $\mathrm{p}-\mathrm{n}$ junction device which are mostly built from semiconductor material, such as silicon. Solar or photovoltaic (PV), cells are used to convert the solar energy of sunlight into electric energy or electricity [1]. As long as there is sunlight, solar cells convert energy and this conversion process diminishes in the evening and during cloudy conditions, and stops completely at dusk and resumes at dawn. It is very fascinating to note that the solar cells convert the most abundant and free form of energy into electricity without using any moving parts and without polluting the environment as compared with the non-renewable energy production methods, such as fossil fuel, hydroelectric, or nuclear energy plants.

The inverter connected to the grid helps in converting the DC electricity produced by the solar panels into the required AC electricity. Grid connected inverters mainly produce AC voltages which have the same frequency and amplitude as the main power grid. Also, if there is more production of power than being consumed the excess power is fed into the main power grid. This helps in saving cost, as many electric companies will meter the electricity fed into the grid and will provide a bill of credit. At night time when there is no sunlight, the required power is supplied by the main power grid as normal. These systems are helping us in reducing the consumption of electricity produced by non-renewable energy sources. Selecting an inverter depends on many factors like output power rating, maximum power point tracking (MPPT) rating, weather, and shade conditions [2]. Inverters are designed to work in a wide range of power conditions from the PV panel that affects the characteristics of the power system. The inverters are selected mainly based on their efficiency and specific application.

The proposed system set up consists of a Chroma programmable Direct Current (DC) power supply, an Aurora inverter, a load, a Chroma digital power meter, and a Chroma programmable Alternate Current (AC) source. The equipment set is connected together in a performance and efficiency simulation study of a smart grid connected photovoltaic system.

\section{Circuit Modelling of solar cell}

The ideal solar cell is modeled by a current source connected in parallel with a rectifying diode, as shown in Figure 1(a).

The corresponding current-voltage (I-V) characteristic is described by the Shockley solar cell Equation [3],

$$
I=I_{p h}-I_{o}\left(e^{\frac{q[V+I R s]}{K_{B} T}}-1\right)
$$

where, $k_{B}$ is the Boltzmann constant in $\mathrm{J} / \mathrm{K}, T$ is the absolute temperature in $\mathrm{K}, q$ $(>0)$ is the electron charge in C, $V$ is the voltage at the terminals of the cell. $I_{o}$ is the diode saturation current and $I_{p h}$ is the photo-generated current. 


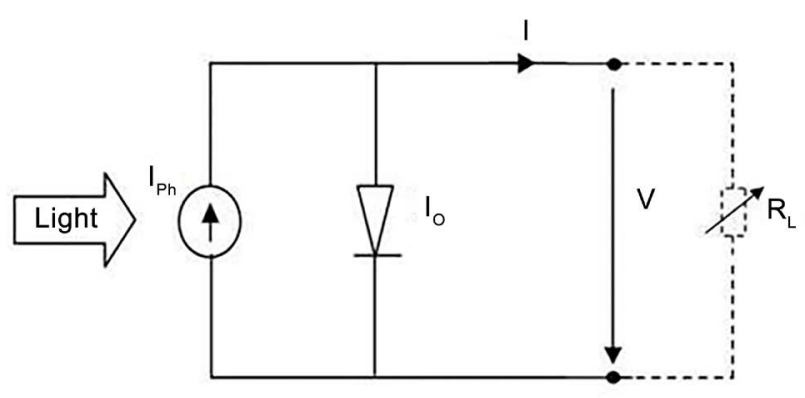

(a)

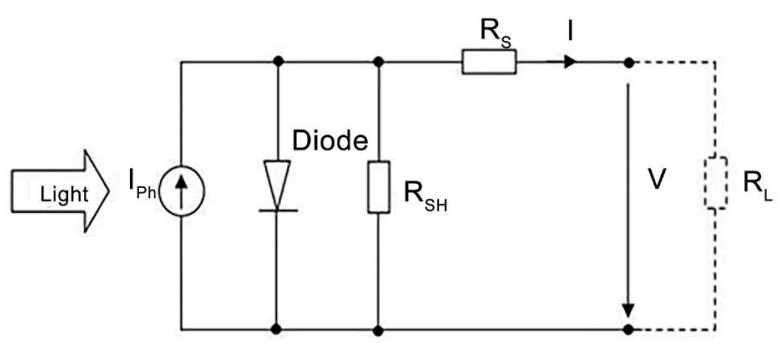

(b)

Figure 1. (a) Equivalent circuit of an ideal solar cell; (b) Practical solar cell equivalent circuit.

Figure 1(b) shows the model of a practical solar cell. It consists of a current source, rectifying diode, and two resistors one in series $(R s)$ and the other in parallel $\left(R_{s h}\right)$ [4]. The series resistance is mainly formed by the bulk resistance of the semiconductor material, the metallic contacts and interconnections, carrier transport through the top diffused layer, and contact resistance between the metallic contacts and the semiconductor. The shunt resistance $\left(R_{s h}\right)$ is formed due to $\mathrm{p}-\mathrm{n}$ junction non-idealities and impurities near the junction, which cause partial shorting of the junction, mainly near the cell edges [5].

The current Equation for the practical solar cell includes the effect of $R s$ and $R_{s h}$ and is given by [4]

$$
I=I_{p h}-I_{o}\left(e^{\frac{q[V+I R s]}{K_{B} T}}-1\right)-\left(\frac{V+I R s}{R_{S H}}\right)
$$

where,

$R s$ is the series resistance $R_{s h}$ is the shunt resistance.

\section{Performance Characteristics of Solar Cell}

Figure 2(a) and Figure 2(b) show the I-V and P-V characteristic curve respectively [3]. To study the performance of solar cells, it is very important to understand the characteristics of solar cells. This mainly includes understanding the basics and improvement of devices, performance evaluation and different methods of measurement. This measurement of characteristics would help to detect and improve the material properties in solar cell production, and also helps in identifying solar cell grades for solar module construction, and to evaluate solar module performances. 


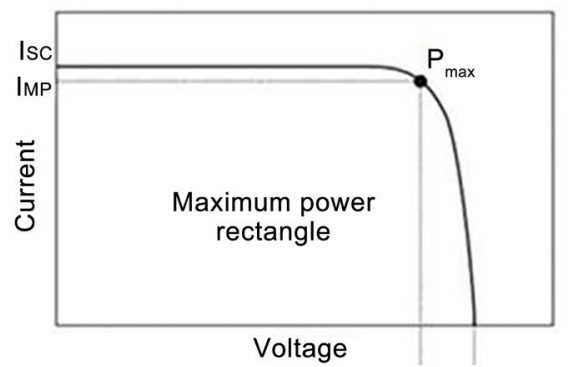

(a)

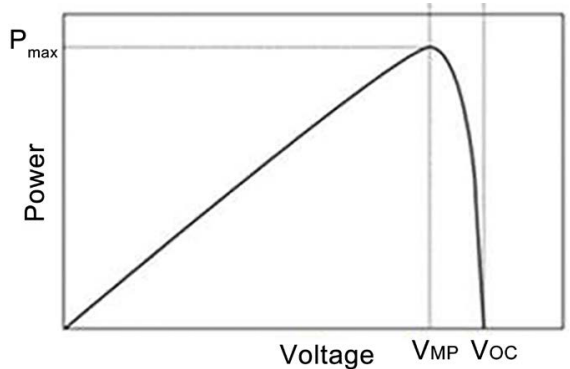

(b)

Figure 2. (a) I-V Characteristics of an ideal solar cell; (b) P-V Characteristics of an ideal solar cell.

Solar cell parameters are found from static characteristics. The solar cell characteristics comprise of open circuit voltage (VOC), short circuit current (ISC), maximum point voltage, maximum point current and maximum point power (VMP, IMP and PMP), and the fill factor (FF). Measurements can be done either under illuminated or under dark conditions.

\section{Irradiance Effects on Characteristic Curves of Solar Module}

Solar irradiance is defined as the rate of energy (power) per unit area and it is usually measured in watt per meter square $\left(\mathrm{W} / \mathrm{m}^{2}\right)$ [6]. Irradiance varies with the movement of the sun and cloud, throughout the day. A higher irradiance means the energy is coming at a faster rate from the sun [7]. The irradiance is directly proportional to the short circuit current and the effect of irradiance on voltage is negligible. Figure 3 shows the I-V and P-V curves of a module being exposed to different amounts of irradiance [8]. There is no change in the shape of the I-V and $\mathrm{P}-\mathrm{V}$ curves but as the irradiance decreases the curve shifts towards lower currents.

The output power of solar cells increases with increase in irradiance. This means that solar cells work best at high level of irradiance. As the amount of sunlight drops, the current and power output of the module drops. However, the voltage is unaffected with lower solar radiation. When looking at the diode equivalent model, as more light strikes the solar cell a larger current is outputted by the current source which represents the photo generated current as seen in Figure 1(a). As the amount of sunlight drops, the current and power output of the module drops. However, the voltage is unaffected with lower solar radiation.

\section{Temperature Effects on Characteristics Curve of Solar Module}

Temperature variations affect the solar cells significantly. With the increase in temperature, the entire I-V curve shifts towards lower voltages and also the panel efficiency decreases. Figure 4 shows that the change in temperature at 


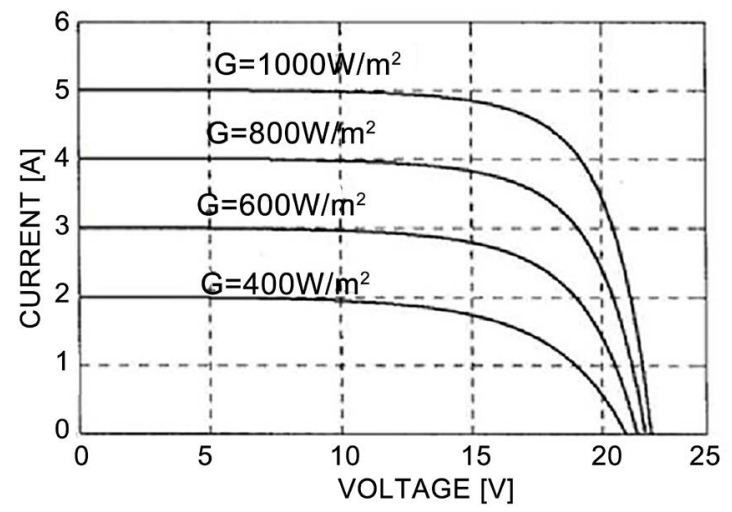

(a)

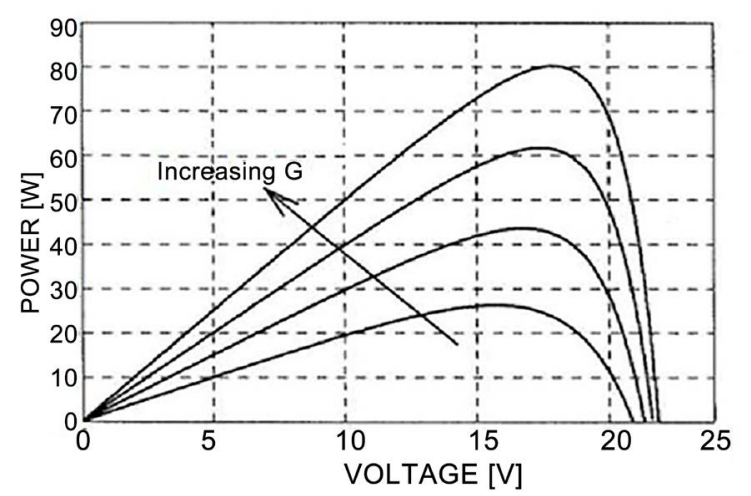

(b)

Figure 3. Irradiance effects on the (a) I-V curve; (b) P-V curve of a Solar cell.

constant irradiance has a strong effect on the open circuit voltage and output power of the cell, but negligible effect on the short circuit current. The change in voltage with temperature is due to change in the diode conduction characteristics [9].

During solar cell design, it is important to consider cold and hot temperature conditions. The amount of change experienced by the solar module, due to temperature change is indicated by the solar module manufacturers in the form of temperature coefficients, which is normally expressed in percentage degree Celsius. Fill factor of the solar cell also decreases with increase in temperature [9]. At higher operating temperature the efficiency of the solar cell decreases because of significant decrease in voltage and reduction in fill factor. Also the maximum power of solar cell reduces due to decrease in voltage, even though there is a slight increase in current density.

\section{Inverter Efficiency Curve}

Inverter efficiency is the ratio of output power to input power of an inverter. The power losses of the inverter depend on inverter load and consists of ohmic losses, switching losses on power switches, and losses caused by temperature variations. Hence the total loss of the inverter is not constant and efficiency mainly depends on load current [10]. The efficiency decreases as the inverter 
gets hot. Hence the inverter has to be installed in a well ventilated location.

Figure 5 shows solar inverter efficiency curve which is a plot of different solar inverter efficiencies at different input power or output power [11]. Different power produced by the inverter at all possible currents that the inverter works at, have different efficiency associated with each current. The peak efficiency represents the highest efficiency that the solar inverter works at [12]. As the current increases the efficiency will also increase sharply until it reaches a peak efficiency point. It will remain close to the peak efficiency point or decreases slightly with increase in current.

\section{Experimental Setup}

The experimental setup of the smart grid photovoltaic system consists of two (2) Chroma DC programmable power supplies in lieu of solar array, an Aurora inverter, a Chroma power meter, a Chroma AC programmable source, safety switch and resistive loads as shown in Figure 6. The Chroma programmable DC power supply with solar array simulation, which is a high power density DC power supply that can provide stable DC output and accurate measurement for voltage and current [13].

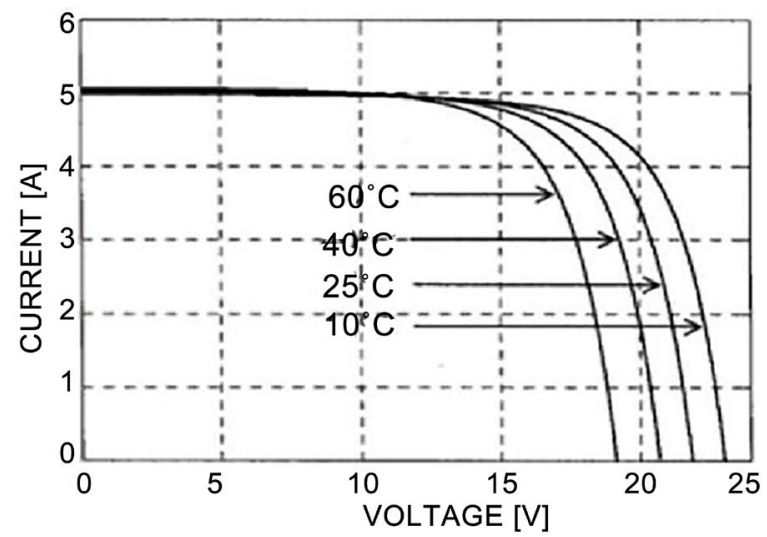

(a)

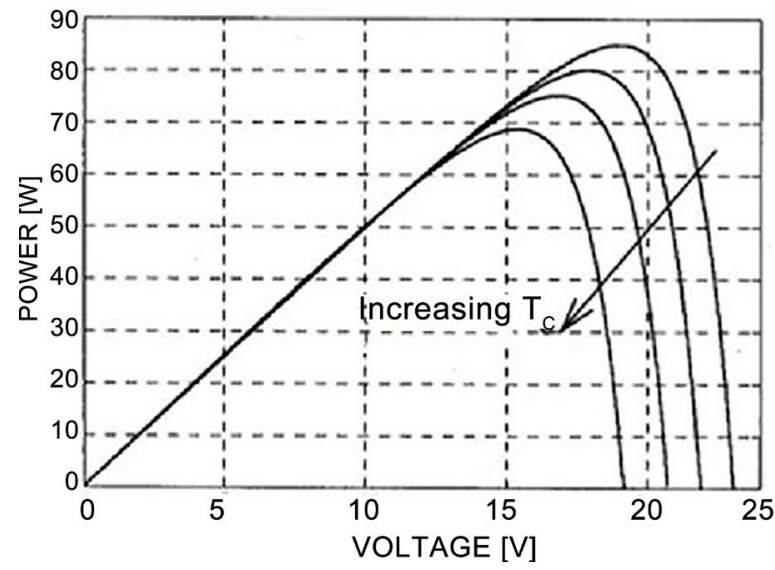

(b)

Figure 4. Temperature effects on the (a) I-V curve. (b) $\mathrm{P}-\mathrm{V}$ curve of a Solar cell. 


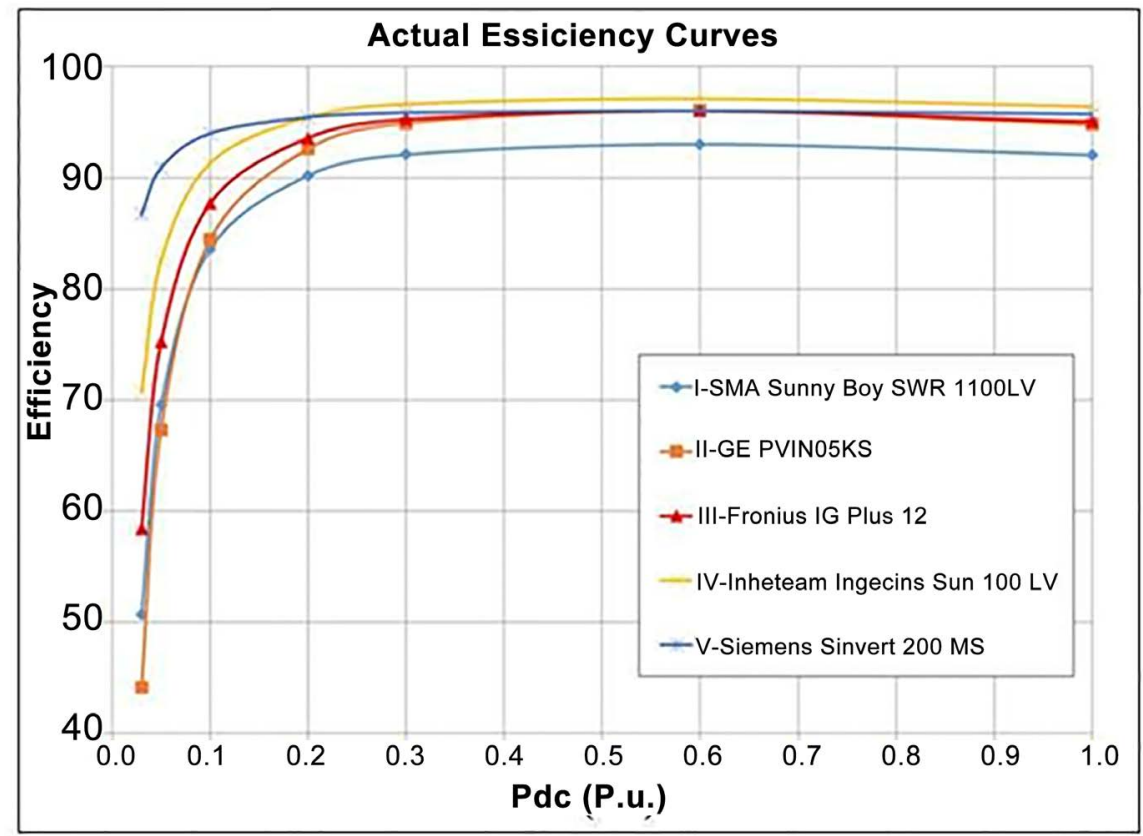

Figure 5. Inverter efficiency curve.

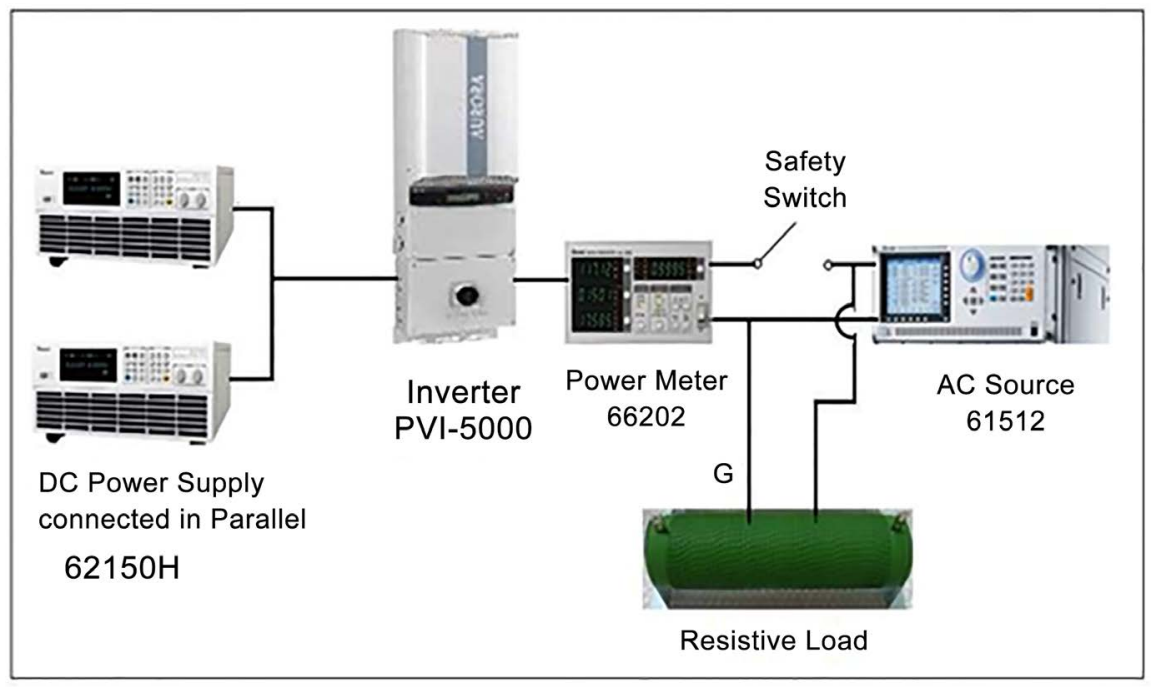

Figure 6. Proposed experimental setup.

The Aurora Inverter is capable of feeding a power grid using the power generated by photovoltaic panels. An Aurora solar inverter converts DC power produced by the solar panels into the required AC power, without using rotating parts but just static power electronic devices.

The Chroma programmable AC source, which provides a low distortion sine wave output for power accuracy [14].

\section{Flowchart}

\subsection{I-V and P-V Curve Flowchart}

Figure 7 shows the flowchart for determining the I-V and P-V curves. All the 


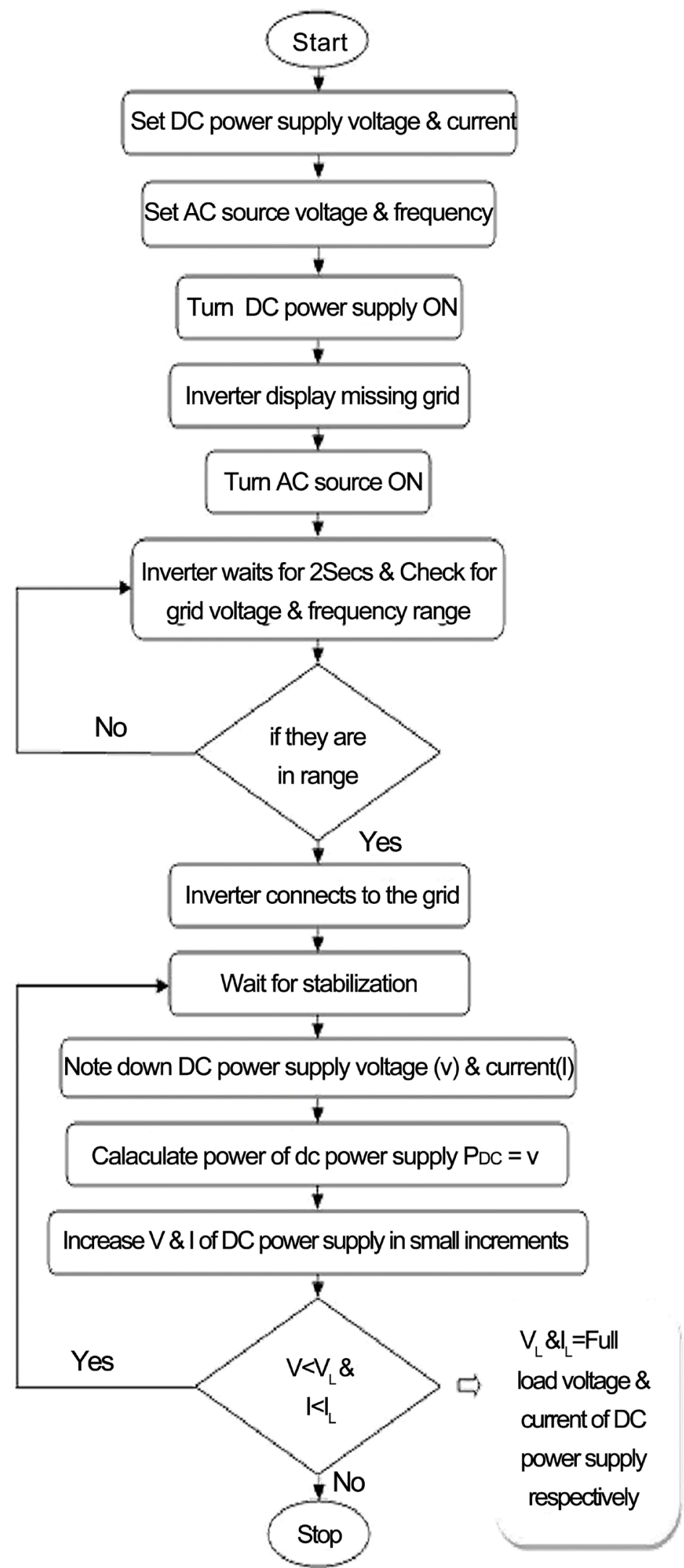

Figure 7. I-V and P-V Curve Flowchart. 
equipment is arranged as shown in Figure 6. The two DC power supplies, safety switch and AC grid are turned on. The MATLAB I-V and P-V curve program is uploaded in the computer. In this program the voltage and the current of DC power supply unit are varied in small increments respectively. When the MATLAB program runs, one of the DC power supply acts as "Master" and other acts as "Slave". The program output shows missing grid on the computer and also on the inverter display. At that moment the AC grid is still "Off", and after a delay, the AC grid turns "On". After 1 or 2 seconds the inverter checks again for grid connection, if the grid voltage and frequency are in the range, the inverter connects to the grid. Once the DC power supply and power meter values are stabilized, the voltage and current of the DC power supply are noted. The output power of the DC power supply from the recorded value of voltage and current is calculated, which is the inverter input power. This process is repeated for various values of voltage and current (in small increments), which is less than full load voltage and current of the DC power supply respectively. The DC power supply output voltage, current and power for various values of input voltage and current are noted down. The current-voltage $(\mathrm{I}-\mathrm{V})$ and power-voltage $(\mathrm{P}-\mathrm{V})$ curves are plotted.

\subsection{Inverter Efficiency Curve Flowchart}

Figure 8 shows the flowchart for the inverter efficiency curve. All the equipment is arranged as shown in Figure 6. The two DC power supplies, safety switch and $A C$ grid are turned on. The MATLAB efficiency curve program is uploaded in the computer. In this program the DC power supply unit voltage is kept constant and the current is varied in small increments. When the MATLAB program runs, one of the DC power supplies acts as "Master" and other acts as "Slave". The program output shows missing grid on the computer and also on the inverter display. At that moment the AC grid is still "Off", and after a delay the AC grid turns "On". After 1 or 2 seconds the inverter checks again for grid connection, if the grid voltage and frequency are in the range, the inverter connects to the grid. Once the DC power supply and power meter values are stabilized, the voltage and current of DC power supply is noted. The output power of DC power supply from the recorded value of voltage and current is calculated, which is inverter input power. The inverter output power from the power meter is noted. The efficiency of the inverter is calculated, which is the ratio of inverter output power by inverter input power. This process is repeated for various values of current (in small increments), which is less than full load current of the DC power supply. The inverter input power and inverter output power are noted, and efficiency of the inverter is calculated for various values of current. The efficiency curve is plotted; this is inverter efficiency $\mathrm{v} / \mathrm{s}$ inverter output power.

\section{Simulation Results}

\subsection{I-V and P-V Characteristics Curve of Solar Array Simulator}

Figure 9(a) and Figure 9(b) show the I-V and P-V curves of solar array simu- 


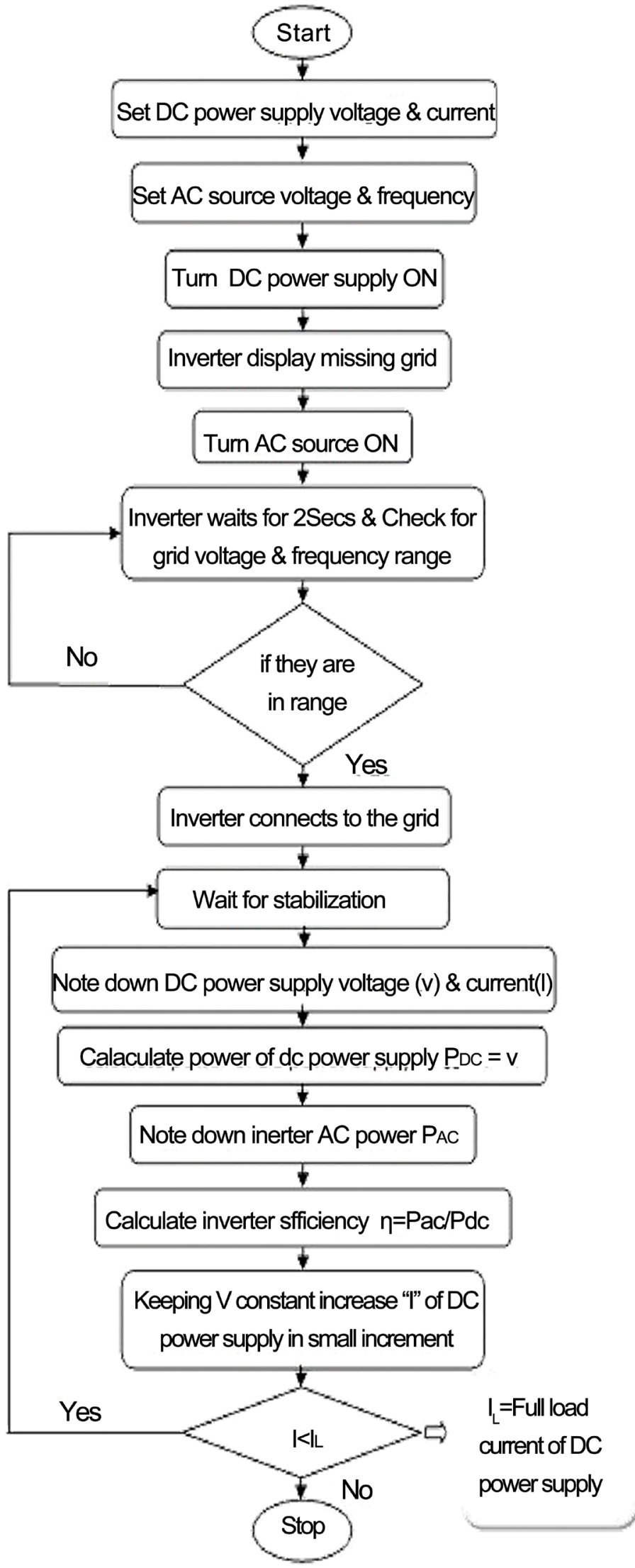

Figure 8. Inverter Efficiency Curve Flowchart. 


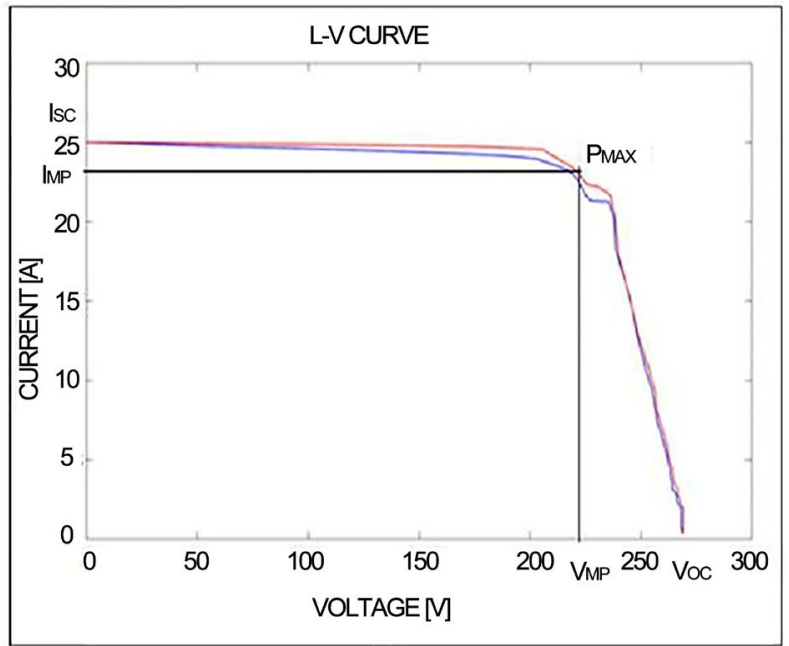

(a)

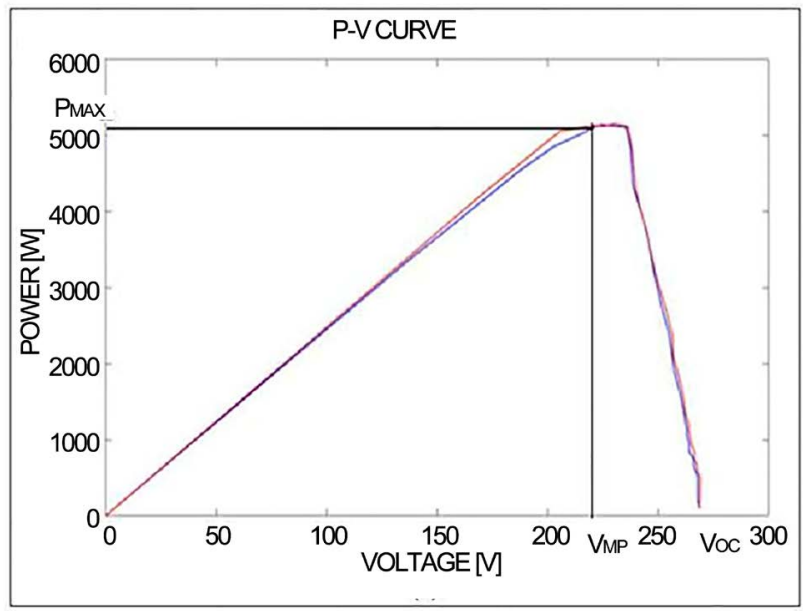

(b)

Figure 9. (a) I-V curve; (b) P-V curve of solar array simulator.

lator; the extent of the I-V curve ranges from the short circuit current (Isc) at zero volts, to zero current at the open circuit voltage (Voc). In the P-V curve, power is calculated as the product of measured current and voltage at each I-V point. At the "knee" of a normal I-V curve, is the maximum power point (Imp, Vmp), the point at which the array generates maximum electrical power. At voltages below Vmp, the external load is relatively independent of output voltage. Near the knee of the curve, this behavior starts to change. The maximum power point, located at the knee of the curve, is the (I, V) point at which the product of current and voltage reaches its maximum value.

\subsection{Irradiance Effects on Characteristics Curves of Solar Array Simulator}

Figure 10 shows the irradiance effects on the I-V and P-V curve of the solar array simulator. With decrease in irradiance the $\mathrm{I}-\mathrm{V}$ and $\mathrm{P}-\mathrm{V}$ curve shifts towards lower currents which means that the change in irradiance has a strong effect on 
L-V CURVE

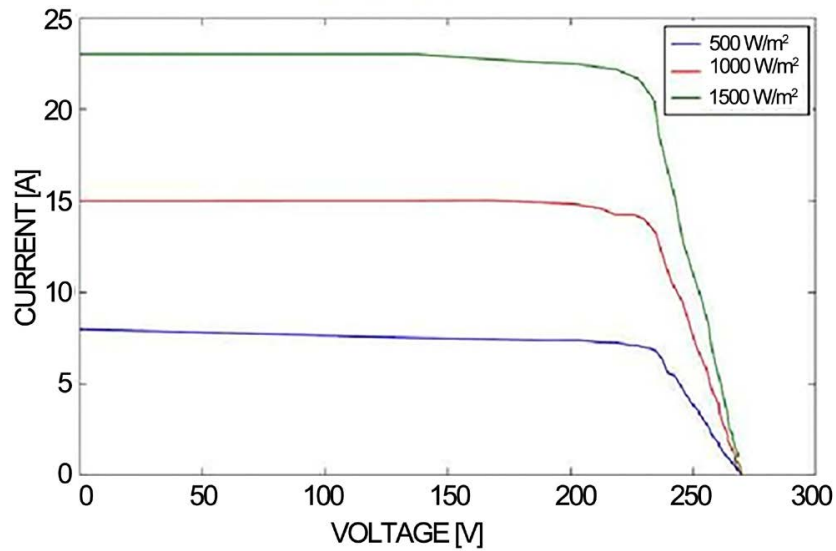

(a)

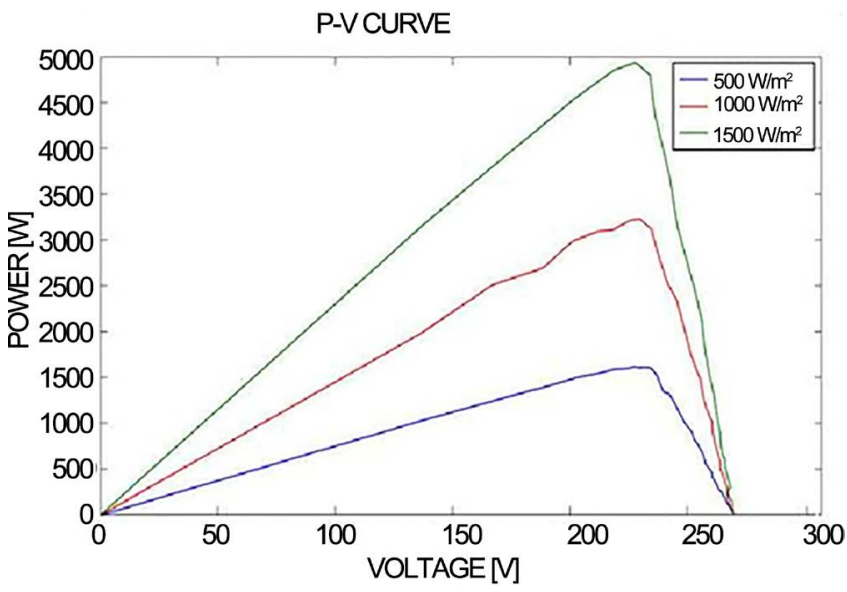

(b)

Figure 10. Irradiance effects on (a) I-V curve; (b) P-V curve.

the short circuit current and the output power of the cell, but negligible effect on the open circuit voltage. There is no change in the shape of the I-V and P-V curve but as the irradiance decreases the curve shifts towards lower currents.

\subsection{Temperature Effects on Characteristics Curves of Solar Array Simulator}

Figure 11 shows the temperature effects on the $\mathrm{I}-\mathrm{V}$ and $\mathrm{P}-\mathrm{V}$ curve of solar array simulator. With increase in temperature the I-V and P-V curve shifts towards lower voltages which means that the change in temperature has a strong effect on the open circuit voltage and the output power of the cell, but negligible effect on the short circuit current. The maximum power of solar cell reduces due to decrease in voltage, even though there is a slight increase in current density.

\subsection{Inverter Efficiency Curves}

Figure 12 shows an inverter efficiency curve which is a plot of different inverter efficiencies at different inverter output power. It also shows different efficiency curves at different voltages for the inverter. The peak efficiency represents the 
L-VCURVE

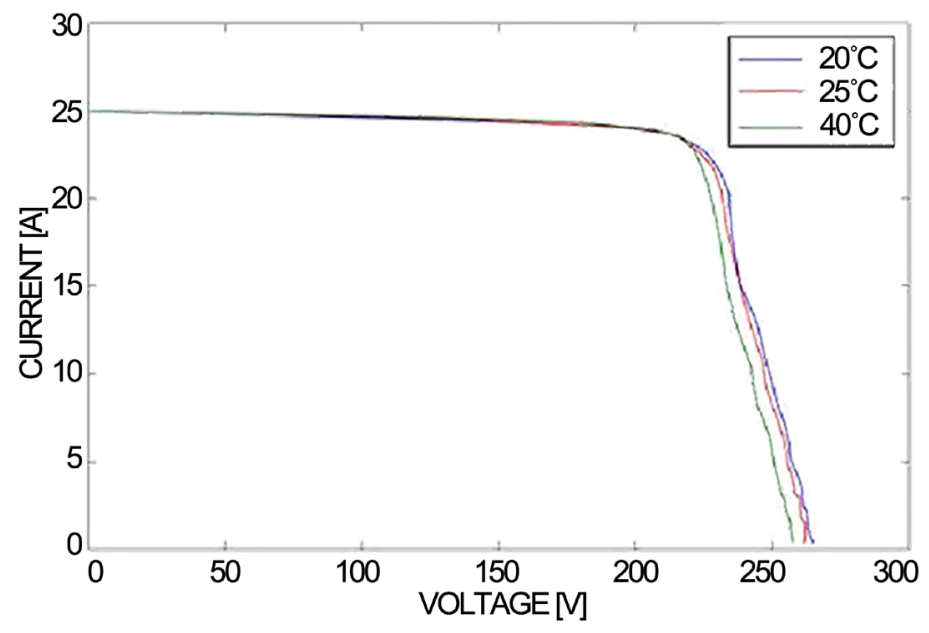

(a)

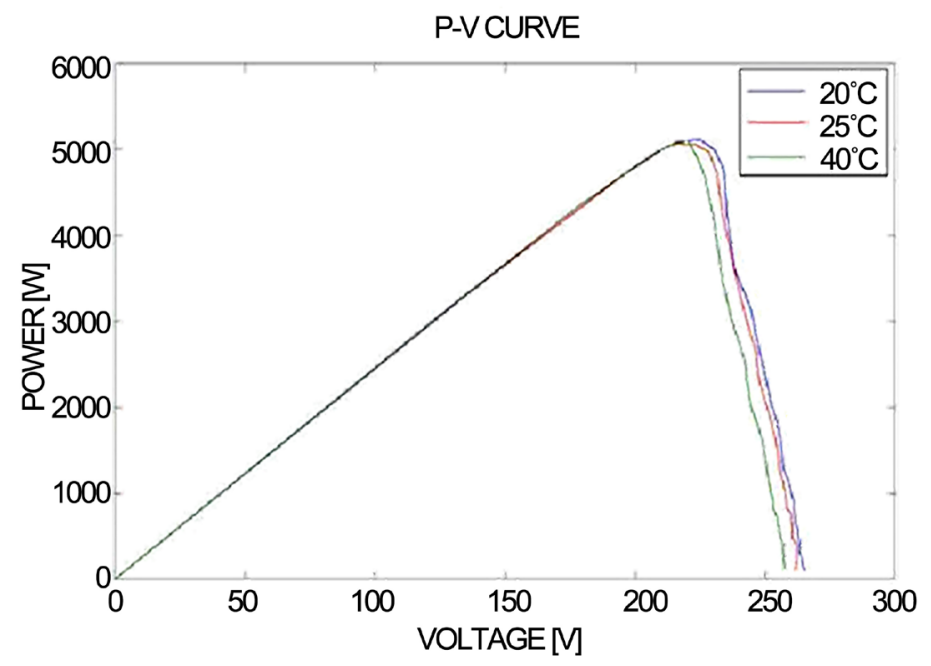

(b)

Figure 11. Temperature effects on (a) I-V curve; (b) P-V curve.

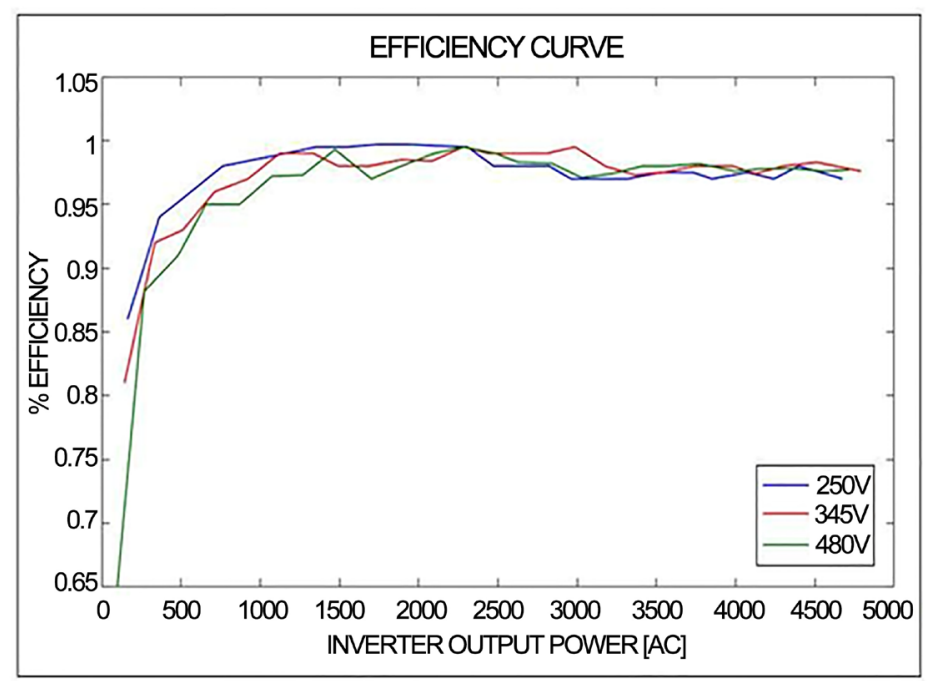

Figure 12. Inverter efficiency curves. 
highest efficiency for the solar inverter. As the current increases the efficiency also increases sharply until it reaches a peak efficiency point. From Figure 10, it can be seen that as current increases the efficiency remains close to peak efficiency point or decreases slightly from $99 \%$ to $97 \%$.

\section{Conclusions}

In this paper, the study of the smart grid connected photovoltaic system is presented. This smart grid connected solar system setup is modeled using DC programmable power supply, an inverter and AC programmable source. The system has been simulated using MATLAB. The results of the solar array simulator show that the characteristics of the I-V and P-V curves generated from the MATLAB are similar to the characteristic curves of an ideal solar cell. In addition, when the irradiance increases, the solar array simulator short circuit current is greatly affected whereas the open circuit voltage remains fairly constant. When the temperature increases, the solar array simulator output voltage drops but there is a negligible effect on the short circuit current. As the current increases the efficiency also increases sharply until it reaches a peak efficiency point and it remains close to peak efficiency point, decreasing slightly with increase in current. The inverter efficiency curves generated from the MATLAB are similar to the actual efficiency curves of different solar inverters [10].

The main contribution of this paper is the development of MATLAB code for smart grid connected photovoltaic system. The MATLAB code developed in this paper is a valuable tool for design engineers comparing different inverters, calculating the optimum efficiency of a given inverter type. The validity of this method has been tested with the results obtained by simulations and measured data. This experiment can be further performed using an actual solar array to verify the simulation results.

\section{References}

[1] Gevorkian, P. (2007) Sustainable Energy System Engineering, the Complete Green Building Design Resource. McGraw-Hill Companies, USA.

[2] Boxwell, M. (2012) Solar Electricity Handbook-A Simple Practical Guide to Solar Energy_Designing and Installing Photovoltaic Solar Electric Systems. Greenstream Publishing, UK.

[3] McEvoy, A.J., Markvart, T. and Castaner, L. (2012) Practical Handbook of Photovoltaics: Fundamentals and Applications. 2nd Edition, Academic Press, Waltham.

[4] Shongwe, S. and Hanif, M. (2012) Comparative Analysis of Different Single-Diode PV Modeling Methods. IEEE Systems Journal, 6.

[5] Rashid, M. (2011) Power Electronics Handbook. 3rd Edition, Butterworth-Heinemann of Elsevier, Burlington.

[6] Arjyadhara, P., Ali, S.M. and Chitralekha, J. (2013) Analysis of Solar PV Cell Performance with Changing Irradiance and Temperature. International Journal of Engineering and Computer Science, 2, 214-220.

[7] Harmon, H.D. and Rasmussen, R. (1996) Temperature, Illmination Intensity and Degradation Factor Effects on Solar Cell Output Characteristics. IEEE Transactions 
on Aerospace and Electronic Systems, Aes-2, 78-84.

[8] Ishengona, F.M. and Norum, L.E. (2002) Design and Implementation of a Digitally Controlled Stand-Alone Photovoltaic Power Supply. Nordic Workshop on Power and Industrial Electronics, 1-5.

http://www.elkraft.ntnu.no/eno/Papers2002/Design-and-impl-norpie02.pdf

[9] Crawley, G.M. (2013) The World Scientific Handbook of Energy. Vol. 3, World Scientific Publishing, Hackensack.

[10] Faranada, R.S., Hafezi, H., Leva, S., Mussetta, M. and Ogliari, E. (2015) The Optimum PV Plant for a Given Solar DC/AC Converter. Energies, 4853-4870.

[11] Faranada, R.S., Hafezi, H., Leva, S., Mussetta, M. and Ogliari, E. (2015) The Optimum PV Plant for a Given Solar DC/AC Converter. Energies, 4853-4870.

[12] Salam, Z. and Rahman, A.Ab. (2014) Efficiency for Photovoltaic Department Head of Electrical Engineering and Interim Dean of the College Inverter: A Technological Review. IEEE Conference on Energy Conversion (CENCON), 175-180.

[13] Chroma Programmable DC Power Supply (with Solar Array Simulation) Manual.

[14] Chroma Programmable AC Source Manual.

Submit or recommend next manuscript to SCIRP and we will provide best service for you:

Accepting pre-submission inquiries through Email, Facebook, LinkedIn, Twitter, etc. A wide selection of journals (inclusive of 9 subjects, more than 200 journals)

Providing 24-hour high-quality service

User-friendly online submission system

Fair and swift peer-review system

Efficient typesetting and proofreading procedure

Display of the result of downloads and visits, as well as the number of cited articles

Maximum dissemination of your research work

Submit your manuscript at: http://papersubmission.scirp.org/

Or contact epe@scirp.org 